\title{
The Verbal and Visual Components of Package Design
}

\section{$\underline{\text { Autobiographical Details }}$}

Ruth Rettie did an MBA at Strathclyde University before spending 10 years in FMCG marketing with Cadbury's, General Foods and Unilever. She joined Kingston University in 1990 as Senior Lecturer in marketing and international marketing.

Carol Brewer graduated in Architecture at Nottingham University before taking an MA in marketing at Kingston University. She is now working as a marketing executive with Notting Hill Housing Trust.

\section{Correspondence}

Ruth Rettie

Kingston University Business School, Kingston Hill, Kingston, UK, KT2 7LB.

$01932-228866$

E Mail R.Rettie@Kingston.ac.uk 


\section{$\underline{\text { Abstract }}$}

It is estimated that 73\% of purchase decisions are made at point of sale ('Frontiers; planning for consumer change in Europe 1996/1997', Henley Centre, 1996. In scanning packs at point of sale, perception is rapid, and quick recognition is important for inclusion in the decision process. Under conditions of rapid perception, there is an advantage for verbal stimuli perceived from the right-hand side, and for non-verbal stimuli perceived from the left-hand side. This advantage probably derives from the laterality of the brain, with word processing generally being handled by the left hemisphere, while the right hemisphere generally processes pictorial matter.

This asymmetry of perception implies that to maximise recall words should be on the right-hand sides of packs, pictures should be on the left. We tested this, using a tachistoscope to measure difference in recall. The results confirm the asymmetry of perception of elements of packaging.

\section{Keywords}

Packaging

Recall

Verbal

Non verbal

Hemispheric laterality 


\section{$\underline{\text { Introduction }}$}

Marketing often involves rapid communication, for example watching a television commercial, driving past a poster, scanning packs in a supermarket, flipping through printed material. Any factors that improve or reduce the success of communication in our "over communicated society" (Ries and Trout, 1986) are of considerable importance, and this research explores the optimisation of pack recall through the positioning of the elements in pack design.

Recent research by the Henley Centre ('Frontiers', Henley Centre, 1996) estimates that 73\% of purchase decisions are made at point of sale; the design of packaging must play a key role at point of sale. The pack design is the 'salesman on the shelf' (Pilditch, 1972), it should ensure that a brand stands out, is recognised, and is included in the products under consideration (Connolly and Davison, 1996). However, there is scant literature and a lack of empirical research (Bloch, 1995)).

Research in psychology on brain laterality, shows that perception is not symmetrical, for instance, words are recalled better if they are perceived from the right-hand side of the individual, while pictorial or non-verbal cues are more successful if coming from the left-hand side. Under conditions of rapid perception, e.g. scanning packs while walking along the aisle in a supermarket, this differential perception and the positioning of the elements in a pack design may make the difference between identifying and missing the item concerned.

The objective of this paper is to relate the concept of brain laterality to pack design; we explore the relationship between the positioning of copy and pictures on different sides of a pack, and the recall of those elements.

Brain Laterality or hemispheric laterality refers to the asymmetry of the brain. Although the left and right sides of the brain are physically symmetrical they are not identical in their functions or organisation; critically, the left hemisphere usually processes language. The design of the human nervous system means that each cerebral hemisphere receives information primarily from the opposite side of the body. This contra-lateral rule applies to hearing, touch, body movement, and to a lesser extent, vision. As the two sides of the brain have different specialisations, there is an inherent bias in the processing of stimuli depending on which side of the body they 
were perceived. For example, stimuli from the right go directly to the left hemisphere, where the language processing facility creates an advantage in the handling of this data. The advantage is small and transient because the two sides of the brain are connected, but the difference has been frequently demonstrated in research, and may be particularly relevant in real situations where many different stimuli compete for attention.

Although brain laterality and its effects have been established for many years there is very little research on its application to marketing communication. In this research we hypothesised that brain laterality would result in an asymmetry in the perception of elements in pack designs.

\section{Brain Laterality}

Evidence on brain laterality comes from three different areas: - analysis of brain damaged patients, observation of the effects of brain surgery, and experiments with normal people. In 1836 Marc Dax noticed an association between the loss of speech and the side of the brain where damage had occurred. Typically speech loss is most likely to occur in patients where the left-hand side of the brain is damaged. This has been confirmed by many subsequent studies (e.g. Wigan 1884).

More recently there has been a lot of research with so-called split brain patients (Gazzinga, Bogen and Sperry, 1962, 1965). These patients have undergone surgery to cut the cortical pathway (called the corpus colloseum) for the treatment of severe epilepsy. This operation results in asymmetries, for example a patient might be able to name an object felt by the right-hand but not name the same object when felt by the left-hand. This happens because the sensory data from the left-hand goes only to the right-hand side of the brain and does not reach the language processing area in the left hemisphere.

Although dramatic discoveries with brain damaged patients indicate differences in hemispheric capabilities, the theories have limited application to normal people where the hemispheres work together with information passing from one side to the other through the corpus colloseum. However, research with normal people shows that there are still asymmetries in the handling of lateralized sensory data in the intact brain. Three types of research has been conducted with normal people:- research using very brief exposures to stimuli, research using 
sodium amytal to anaesthetise one side of the brain, and more recent research which directly measures brain wave activity and its localisation.

Research using very brief exposures is most relevant to the handling of marketing stimuli in real situations, and this methodology has been adapted for this research. In the intact brain the lateralized message is transferred to the other side of the brain almost instantaneously; however, researchers have found significant differences in the handling of very brief stimuli particularly when different stimuli are presented to the two sides at the same time. Research found many differences between the two hemispheres, with the left generally having an advantage in the cognitive processing of verbal material and the right hemisphere showing superiority in music, interpretation of emotions, and the matching of non-verbal material. The earliest research involved auditory stimuli and the sense of hearing (Kimura, 1961, 1966), but, subsequently, similar results have been achieved with non-verbal and other stimuli.

In the case of vision, signals from the outer sides of the visual field are processed initially by the opposite brain hemisphere. Both eyes perceive the visual area, but information from the outer right visual field initially goes only to the left hemisphere, while information from the outer left visual field initially goes directly to the right hemisphere. The vast majority of visual laterality research has used a tachistoscope to control the length of exposure to the visual stimulus. The design of the tachistoscope also encourages respondents to look straight ahead. The theory makes the assumption that the eyes are fixed straight ahead, and do not scan across the visual field, and therefore respondents are initially asked to focus on a central fixation point. This technique using a tachistoscope, which is common to both brain laterality and pack design testing, has been adapted for this research.

Brain laterality research has found that verbal stimuli are recalled better when they are on the right of the visual field, and non-verbal stimuli recall is better when on the left-hand side of the visual field. With accuracy of recall as the dependent variable there is now a long history of reports of a right visual field superiority for letter and digit stimuli (Bryden and Zurif 1969; Seamon 1974; Madden and Nebes 1980). Research has shown that the left visual field has an advantage in the perception of non-verbal material including images, colour (Davidoff, 1976) brightness discrimination (Davidoff, 1977) and depth perception (Kimura, 1974). 
The research described above typically involved very simple stimuli. Research suggests that with complex stimuli there is more likely to be a bi-hemispheric response than an asymmetric response; however, it is unclear whether the two hemispheres process stimuli independently, interactively, or co-operatively (Rothschild et al, 1988).

\section{$\underline{\text { Handedness }}$}

Brain laterality is related to handedness in that left-handed people tend to have different brain lateralization from right-handed. This has been demonstrated clinically (Levy et al.) using sodium amobartital to anaesthetise one hemisphere at a time. In this study $90 \%$ of right-handers were found to have speech localised in the left hemisphere which compared to $70 \%$ of left-handers. As approximately $89 \%$ of the population are right-handed (Annett, 1972; Bryden, 1979) most research has focused on right-handed subjects.

\section{$\underline{\text { Pack Design }}$}

Pack design literature has concentrated on the growing importance of design in packaging and the role of packaging as a vehicle for communication and branding. Whilst there is considerable literature on pack design research techniques, these have mainly been applied to individual pack designs. There is little general empirical research.

The role of pack design changed with the move to self service (Danger, 1987; Behaeghel, 1991), and the pack became an essential part of the selling process, (Danton de Rouffignac, 1990). The move to larger supermarkets and increased segmentation of markets has led to the proliferation of products, so that packaging has to work in a more crowded competitive context both in the retail environment and in the kitchen (Thompson, 1996). Impulse buying is also increasing, with an estimated half of all grocery purchases being unplanned, (Cobb and Heyer cited in Philips and Bradshaw, 1993). A quantitative survey by the Henley Centre concluded that $73 \%$ of purchase decisions were made at point of sale. (Frontiers, 1996). The tendency to a weekly shop, and the large number of items purchased at one stop, leads to less time to make the purchase decision, and consequent need for the pack design to work harder. 
It is suggested that packaging may be the biggest medium of communication (Behaeghel, 1991, Peters, 1994). Three reasons are given for this: its extensive reach to nearly all purchasers of the category, its presence at the crucial moment when the purchase decision is made, and the high level of involvement for users who will actively scan packaging for information. This involvement of the user makes the packaging an essential element in branding, both in the communication of brand values and as an essential part of the brand (Connolly and Davidson, 1996). The design of the pack itself may be an incentive to buy, (Hall, 1993).

Bloch (1995) proposed a model of consumer response to product form. In Bloch's model product form determines psychological response, moderated by individual characteristics and situational factors, (see Figure 1). Psychological response is then divided into cognitive and affective responses (based on the distinction made by Bitner, 1992).

Take in Figure 1.

There is some debate whether cognitive response is based upon holistic visual perception, (Jones, 1991), linear processing of the different elements, (Durgee, 1988) or both (Bloch, 1995). Bloch's model concentrates on response to product form and discusses the problem of gaining attention in cluttered markets. Berkowitz (1987) and Dumaine (1991) discuss this further. Meyers-Levy and Tybout (1989) show that the degree of category congruity influences information processing, demonstrating that consumers prefer new products that demonstrate moderate incongruity with existing products. Incongruity may also be relevant in getting noticed on a cluttered shelf.

In pack design research there are three main ways of assessing packaging, image tests, usage tests and visibility tests, (Schwartz, 1971). Image tests use traditional qualitative and quantitative research to assess consumer attitudes, preferences and the message communicated. Usage tests examine functionally related attitudes towards the packaging, and generally involve in-home placement tests.

Visibility or visiometric tests are designed to evaluate the legibility of pack graphics, the relative impact of different pack elements, and the relative impact of different designs; they include the use of a tachistoscope, angle and blur meters, and eye movement tests, (Stern, 1981). Tachistoscopy has been used to assess pack 
visibility since the Second World War, when it was used in training in the recognition of aircraft silhouette.

(Swope, 1981). The tachistoscope has an electronic shutter, which allows one to control the exposure of the pack design precisely (e.g. $1 / 100$ of a second). It has been used to measure the impact of the packaging, the legibility of the pack graphics, and the shelf standout of different packs. One disadvantage of the tachistoscope is that it is used in an artificial environment, the respondents are not actually shopping, and the impact in store may be different. In addition, while it may tell you what the subject sees, it does not tell you what is communicated.

\section{Marketing Applications of Brain Laterality}

There is relatively little research in this area. Hansen (1981) reviews the laterality literature and identifies eight techniques for measuring laterality including the tachistoscope. He discusses the implications for consumer behavior in five areas: attention processes, pictorial communications, choice behavior, involvement, and individual differences. Ellis and Miller (1981) found that right-handed respondents preferred print ads. with verbal copy on the right and pictorial material on the left. Janiszewski (1988) found non-attended verbal ads. are preferred when placed on the right of attended material, while the converse is true of non-attended pictorial print ads. Janiszewski (1990) found a preference for brand names, which were placed to the left of verbal copy or to the right of pictorial material.

Brain wave or electroencephalograph (EEG) analysis has been used on both advertising and pack design (Weinstein 1981; Rothschild et al 1988). This method is based on 'Alpha' and 'Beta' brain waves. When the 'Alpha' wave is present, the respondent is believed to be un-stimulated by the environment, whereas the 'Beta' wave is thought to indicate 'involvement' or stimulation by the environment. Analysis of brain wave activity has been used to evaluate the different effects of specific pack designs on the two sides of the brain. The efficacy of this method has been challenged because of the difficulty in interpreting brain wave analyses, and great variance of EEG response across subjects. Several EEG studies of complex television stimuli (Weinstein et al, 1980; Alwitt, 1985) failed to find evidence of lateralization, however, using a different method Rothschild et al (1988) found hemispheric differences in EEGs which corresponded to the verbal and non-verbal nature of the stimuli. 


\section{Methodology}

Applying the research on brain laterality to the optimisation of the elements of pack design we have derived the following hypotheses for this research. All the hypotheses relate only to right-handed people.

\section{Hypothesis 1.}

The left-hand side of the brain, which processes verbal stimuli, will directly receive verbal stimuli (i.e. copy) from the right-hand side of the pack, therefore

H1: Pack copy will have a higher recall when it is on the right-hand side of the pack.

\section{Hypothesis 2.}

This is the converse of Hypothesis I and relates to pictures or other non-verbal material. The right-hand side of the brain, which processes non-verbal stimuli, will directly receive non-verbal stimuli (e.g. product photographs) from the left-hand side of the pack, therefore

$\mathrm{H}_{2}$ : Non-verbal material will have a higher recall when it is on the left-hand side of the pack.

The research was carried out amongst Kingston University students. The sample consisted of 150 students; previous research using a tachistoscope suggested 50 as a minimum for brand recall (Schwartz, 1975). The sample was split equally between women and men because research shows that brain laterality differs between the sexes, with women generally showing less laterality.

The stimuli were 5 sets of packaging for grocery products. Each set consisted of an original pack design and a pack where the laterality of the copy and/or pictorial matter was reversed, (i.e. the packs were mirror images). The adapted packs were of a high standard and could not be differentiated from the originals. For example we used a PG Tips tea bag pack which had a 'Cuddly Chimps Offer' and showed a picture of two chimps. Plate 1 shows the original and laterally reversed packs. The packs were chosen for convenience in that their size and shape made it feasible to use in the tachistoscope and their design made it feasible for us to produce a 'mirror' image. 
Using a tachistoscope to control the length of exposure to the pack, respondents were shown each pack front for 500 milliseconds. Previous research in psychology (Graham in Beaumont, 1982) had recommended exposures of 150 - 200 milliseconds for simple words and shapes. Due to the complexity of the stimuli we conducted a pilot test to determine the length of exposure, which is critical. In the pilot we tested times of 300 milliseconds, 500 milliseconds and 700 milliseconds, all under a constant illumination level. We found that after 300 milliseconds respondents could answer very few questions, and at 700 milliseconds they answered nearly all the questions correctly. We chose 500 milliseconds as this is sufficiently quick to prevent respondents scanning the packs, and/or transference of information from one side of the brain to the other. Respondents were asked to look straight ahead and initially focus on the centre of the pack, this was to avoid saccadic or scanning eye movement.

Each respondent saw 5 packs, but only one version of each pack. Pack order was rotated to avoid order bias. This was done using random number tables to generate six different order sets to ensure that an equal number of respondents saw each of the two versions of the packs. For each pack half of the respondents were shown the original pack and half were shown a 'mirror' image which reversed key copy and visual elements. After seeing each pack respondents were asked to fill in a simple questionnaire which included unprompted and prompted recall of the elements of the pack design and overall visual appeal of the pack. Altogether there were fourteen recall questions about elements of the pack that were reversed from one side of the pack to the other. These consisted of nine questions about copy (to test hypothesis $\mathrm{H}_{1}$ ) and five questions about visual elements (to test hypothesis $\mathrm{H}_{2}$ ). The number of questions of each type, and the nature of the questions varied according to the pack elements that were laterally reversed. For example for the tea bags the questions were: "How many characters were on the pack?" (Visual element), "How were the characters described?", "How many bags did the pack contain?", (Verbal elements). Consequently the total number of questions of each type depended on the design of the packs used. Respondents were tested on handedness, using an adaptation of a standard questionnaire (Bryden 1982), and left-handers were excluded from the research.

\section{Findings}

\section{Hypothesis $\mathrm{H}_{1}$}


We hypothesised that, for right-handed respondents, copy would have better recall when positioned on the righthand side of the pack. In seven of the nine questions relating to copy, recall was improved when copy was on the right-hand side. In two cases this improvement was significant at a 95\% confidence level, in another five cases it was directionally better. Overall, taking all cases together, the result was marginally significant. For two questions (which related to the same pack) recall was better marginally when pack copy was on the left-hand side, contrary to Hypothesis $\mathrm{H}_{1}$, (see Table 1). For some packs both verbal and non-verbal elements were laterally reversed, for others, only one type of element was reversed depending on the pack design, so that there was no reversal of verbal elements for the Findus Pizza Pack, and no reversal of pictorial element for Arctic Roll.

Take in Table I.

\section{Hypothesis $\mathbf{H}_{2}$}

This hypothesis anticipated that pictorial (i.e. non-verbal) elements would have better recall when positioned on the left-hand side of the pack. Five questions were asked about pictorial elements. In each case recall was better when the pictorial element was on the left-hand side; in one case the difference was significant at the $95 \%$ level, in the others it was directionally better, (see Table II). Overall, taking all cases together, the result was significant.

Take in Table II

\section{Discussion of the Results.}

We asked 13 questions relating to the recall of elements. In all except two cases, the findings were consistent with the hypotheses, recall was better for verbal stimuli when the copy was on the right-hand side of the pack, and better for non-verbal stimuli when it was on the left-hand side of the pack. In three cases the difference was significant, in each case confirming the hypotheses. Taking all the cases together, the difference was significant with an advantage both for verbal copy on the right and pictorial material on the left.

In some cases the difference was dramatic, for example, nearly twice as many respondents who saw the PG Tips promotion on the left hand side of the pack were able to correctly recall the promotion. This difference could have an enormous effect on the promotion's effectiveness. 
In the case of Findus Pizza our view that the price flash acts as a pictorial element is debatable, but the results are consistent with this view. In the Arctic Roll pack the results were directionally opposed to hypothesis $\mathrm{H}_{1}$, that copy is better on the right hand side of the pack. This may be because the copy is contained in a complex graphic device which acts as a pictorial element. Elements of pack design may not work separately, but may be perceived as a group or cluster of elements. In this case the optimum positioning of pack flashes would be on the left irrespective of the nature of the flash.

We therefore suggest a further hypothesis, $\mathrm{H}_{3}$, flashes, which contain copy, act as pictorial elements and therefore, have better recall when positioned on the right hand side of the pack.

In two cases (PG Tips and Arctic Roll) the actual pack graphics maximised recall of the lateral elements. In two cases (Weight Watchers Cookies and Findus Pizza) the pack graphics were not optimal. In the fifth case, Harrington's Log, the actual pack carries both alternatives on different faces.

\section{Limitations}

The research used only five different packs. In choosing them we were constrained by the dimensions of the tachistoscope plate size, and by the need to create high quality laterally inverted packs. This small number of packs, and their similar dimensions may have biased the results. Pack design, and consequent recall of pack elements vary enormously, and with this small number of packs one cannot draw implications for package design in general. The research needs to be replicated on a much larger scale, both with a larger research sample and with a greater number of packs.

This research was done using existing packs; there may be bias in that respondents may have been previously exposed to some of the packs, and therefore may know the answers to the questions without having to see the relevant elements. 
Respondents were asked to complete the questionnaires themselves, which requires left brained linguistic processing. This may also have introduced a bias, although it is likely that the act of choosing a pack from a shelf would also involve the left-hemisphere. Our results relate only to recall, which again may introduce bias towards the left, language-processing hemisphere. We would recommend that the research be replicated using a longer exposure to assess recognition rather than recall.

There is considerable difference between viewing a pack for a few milliseconds through a tachistoscope and scanning the shelves of a supermarket. It is possible that the laboratory nature of the experiment may have introduced bias. There is scope for further research using packs in more realistic situations or in actual stores.

In some instances it was difficult to decide whether a stimulus was verbal or non-verbal; for instance we decided that a very bright star-shaped flash was a pictorial element, despite the fact that it contained a number. On the other hand, we treated the words '40 bags' on the PG Tips pack as a verbal element.

The methodology used, which was adopted from numerous studies by psychologists, depends on fixation. If respondents do not follow the instructions, the asymmetry found in this research (and in numerous studies in psychology) may not be caused by brain laterality.

The asymmetry of perception of packaging could be caused by the English method of reading from left to right. From the marketing perspective, however, the existence of a bias in recall of copy on one side is significant whatever the cause. This could be tested by replicating the research using consumers with languages (Chinese, Japanese, Arabic etc) which are read from right to left.

The research methodology assumes a linear rather than a holistic visual perception.

\section{$\underline{\text { Research Implications }}$}

The implication of this research is that recall of pack elements is likely to be influenced by their lateral positioning on the pack, as well as the usually recognised factors such as font style, size, colour, etc. For some pack copy, such as brand name or flavour description it is important to enhance recall and this research suggests 
that these elements should therefore be placed centrally or on the right-hand side of the pack. For other elements, such as an unappealing legal description or a product disclaimer, recall is not desired, and these elements should be placed on the left-hand side.

This research has concentrated on verbal elements such as pack copy, but there is some evidence that to maximise recall, pictorial elements, such as product photography, should be positioned on the left-hand side of the pack.

We found limited evidence that pack flashes function as pictorial devices despite containing verbal elements, and these should therefore be positioned on the left-hand sides of packaging. This is an important result for the design of price and promotional flashes, which are usually located laterally, and where rapid perception may be crucial.

The theory suggests that brain laterality will only affect material on the outer sides of the pack. Central stimuli are seen by both eyes and therefore received simultaneously by both sides of the brain. Consequently, there is no evidence of laterality for centralised elements of packaging. Application of this would suggest centralising key elements such as brand names whenever possible.

Relating this research to the packaging model discussed earlier, Bloch (1995), we have shown that the laterality of verbal and non-verbal elements of the product form will, under the situational factor of rapid perception for right-handed individuals, affect cognitive response (i.e. product beliefs). This is shown in Figure 2.

\section{$\underline{\text { Future Research }}$}

This research needs to be replicated on a much larger scale. Further research could look at recognition rather than recall, and also investigate whether elements are perceived as a group, or individually.

There is scope for further research in other areas of marketing. Brain laterality may have many implications for marketing, both in terms of explanation and optimisation. For instance, it is one rationale for the improved recall of print advertisements on right-hand pages of printed material. It also has actionable consequences for 
marketing communications, especially advertising and packaging. Television commercials are an obvious example; copy is often superimposed on the commercial. In some cases, e.g. a logo or a telephone number, it is desirable to maximise recall; on the other hand it is may be preferable to minimise recall of a legally required disclaimer. There is further scope for research in other advertising areas such as print and outdoor advertising. The theory can also be related to merchandising and the positioning of packs relative to traffic flow in stores. One would expect products on the right-hand side of the aisle to sell better.

Brain laterality applies to aural as well as visual senses, there is a similar asymmetry in the processing of sounds. The right ear advantage in the processing of verbal communication may be relevant to telesales where operators usually have the phone on one side only. One could predict greater sales when phones are positioned against the right ear.

Research techniques now exist for scanning the brain and observing which areas are active. As these techniques are developed and become more widely available one can envisage monitoring brain activity during exposure to packaging or advertising, and directly observing how the brain is aroused by different stimuli.

It is estimated that approximately $40 \%$ of marketing budgets are allocated to pack design (Millward Brown Market Research, cited in Campaign, 1997); this reflects the importance of pack design in product marketing. In many cases it is important to optimise perception of pack elements, for example, logos, brand slogans, flavour, visual appeal, promotional offers, etc. In other instances, such as legally required disclaimers, optimal positioning would minimise perception. The optimisation of the positioning of elements of pack design is consequently very important to operational marketing.

\section{$\underline{\text { References }}$}

Alwitt, L. F. (1985), "EEG Activity Reflects the Content of Commercials”, in Alwitt, L.F. and Mitchell A. A. (Eds.) Psychological Processes and Advertising Effects, Lawrence Erlbaum Associates, New York, pp. 201-217. Annett, M. (1972), “The Distribution of Manual Symmetry”, British Journal of Psychology, Vol 63, pp. 343358. 
Beaumont, J.G. (1982), Divided Visual Field Studies of Cerebral Organisation, Academic Press, London.

Behaeghel, J. (1991), Brand Packaging- the Permanent Medium, Architecture Design and Technology Press, London.

Berkowitz M. (1987), “ Product Shape as a Design Innovation Strategy”, Journal of Product Innovation Management, Vol 4, pp. 274-283.

Bitner, M.J. (1992), “ Servicescapes: The Impact of Physical Surroundings on Customers and Employees”, Journal of Marketing, Vol 56, pp. 57-71.

Bloch, P. H. (1995), “ Seeking the Ideal Form: Product Design and Consumer Response”, Journal of Marketing, Vol 59, pp. 16-29.

Bryden, M. (1982), Laterality - Functional Asymmetry in the Intact Brain, Academic Press, London.

Connolly, A, and Davidson, L. (1996), “How Does Design Affect Decisions at Point of Sale?”, Journal of Brand Management, Vol 4 No2, pp. 100-107.

Davidoff J.B. (1977), “ Studies with Non-verbal Stimuli” in Beaumont, J.G. (Ed.), Divided Visual Field Studies of Cerebral Organisation, Academic Press, London, pp. 29 - 55.

Davidoff, J.B. (1976), "Hemispheric Sensitivity Differences in the Perception of Colour”, Quarterly Journal of Experimental Psychology, Vol 28, pp. 387-394.

Danger, E. (1987), Selecting Colour for Packaging, Gower Technical Press, London.

Danton de Rouffignac, P. (1990), Packaging in the Marketing Mix, Butterworth-Heinemann, Oxford.

Dumaine, B. (1991), “Designs that Sells and Sells and........, Fortune, March 11 1991, pp. 86-94.

Durgee, J.F. (1988), “Product Drama”, Journal of Advertising, February/March 1988, pp. 42-49.

Ellis, A.W. and Miller, D. (1981), "Left and Wrong in Adverts: Neuropsychological Correlates of Aesthetic Preferences”, British Journal of Psychology, Vol 72 pp. 225 - 229.

Frontiers (1996), "Planning for Consumer Change in Europe 1996/1997”, Henley Centre. Cited in Connolly and Davison (1996) op.cit, pp. 100-101.

Gazzinga, M.S., Bogen,J.E., and Sperry, R.W. (1962), "Some Functional Effects of Sectioning the Cerebral Commissures in Man", Procedures of the National Academy of Science, Vol 48, pp. 1765-1769.

Gazzinga, M.S., Bogen, J.E., and Sperry, R.W. (1965), “Observations on Visual Perception after Disconnexion of the Cerebral Hemispheres in Man”, Brain, Vol 88, pp. 221-236. 
Hall, J. (1993), “Brand Development: How Design Can Add Value”, Journal of Brand Management, Vol 1 No 2, pp. 86-95.

Hansen, F. (1981) “Hemispherical Lateralization: Implications for Understanding Consumer Behavior” Journal of Consumer Research, Vol 8, pp $23-36$.

Janiszewski, C. (1990), “The Influence of Print Advertisement Organization on Affect Toward a Brand Name”, Journal of Consumer Research, Vol 17 pp. 53 - 65.

Janiszewski, C. (1988), "Preconscious Processing Effects: The Independence of Attitude Formation and Conscious Thought”, Journal of Consumer Research, Vol 15 pp. 199 - 209.

Kimura, D. (1961), “Cerebral Dominance and the Perception of Verbal Stimuli”, Canadian Journal of Psychology, Vol 15, pp. 166-171.

Kimura , D. (1966), "Dual Function Asymmetry of the Brain in Visual Perception”, Neuropsychologia, Vol 4, pp. 275-285.

Kimura , D. and Davidson, W. (1975), "Right Arm Superiority for Tapping with Distal and Proximital Joints", Journal Hum. Mov. Stud. Vol 1, pp.199-202.

Madden, D.J. and Nebes, R.D. (1980), “Hemispheric Differences in Memory search”, Neuropsychologia, Vol 18, No 6 pp. $665-673$.

Meyers-Levy, J. and Tybout A.M. (1989), “Schema Incongruity as a Basis for Product Evaluation”, Journal of Consumer Research, Vol 16, pp. 39-54.

Millward Brown Research, "Packaging Design”, cited in Campaign, March 31 1997, pp.5.

Philips, H. and Bradshaw, R. (1993), "How Customers Actually Shop: Customer Interaction with the Point of Sale”, Journal of the Market Research Society, Vol 35, No1 pp. 51-62.

Pilditch, J. (1972), The Silent Salesman, Business Books Ltd, London.

Peters, M. (1994), “Good Packaging Gets Through to Fickle Buyers,” Marketing, January 20 1994, pp. 8. Ries, A and Trout, J. (1982), Positioning: The Battle for your Mind, Warner, New York.

Rothschild, M.L., Hyun, Y.J.,Reeves, B.,Thorson,e. and Goldstein, R., (1988) “Hemispherically Lateralized EEG as a Response to Television Commercials”, Journal of Consumer Research, Vol 15, pp. 185 - 198.

Seamon, J. G., (1974), “Coding and Retrieval Processes and the Hemispheres of the Brain”, in Hemisphere

Function in the Human Brain eds. Dimond S. J. and Beaumont J. F. London, Elekscience pp. 184 - 203.

Schwartz, D. (1971), “Evaluating Packaging”, Journal of Advertising Research, Vol 11, pp. 29-32. 
Schwartz, D. (1975), “T Scope Package Test Sample Size”, Journal of Advertising Research, Vol 15. pp. 45-57.

Stern. W. (1981), "Package Design Research: The State of the Art”, in Stern, W. (Ed.), $\underline{\text { Handbook of Package }}$

Design Research, John Wiley and Sons, U.S.A, pp. 2-22.

Swope, L. (1981), “Visiometric Testing: How a Package Communicates”, in Stern, W. (Ed.), Handbook of Package Design Research, John Wiley and Sons, U.S.A, pp. 141-148.

Thompson, L. (1996), "Lifting the Lid on Packaging Research", The Journal of Brand Management,

Vol 3 No 5, pp.289-295.

Weinstein, S., Appel, V., and Weinstein, C., (1980), "Brain-Activity responses to Magazine and Television Advertising," Journal of Advertising Research, Vol 20 No 3, pp. 57-63.

Weinstein, S. (1981), "Brain Wave Analysis: The Beginning of the Future of Package Design Research", in Stern, W. (Ed.), Handbook of Package Design Research, John Wiley and Sons, U.S.A, pp. 492-505.

Wigan, A. (1884), The Duality of the Mind: A New View of Insanity, Longman, London.

Zurif E.B., and Bryden, M. (1969): Familial Handedness and Left-right Differences in Auditory and Visual Perception. Neuropschologia, Vol 7, pp. 179-187. 


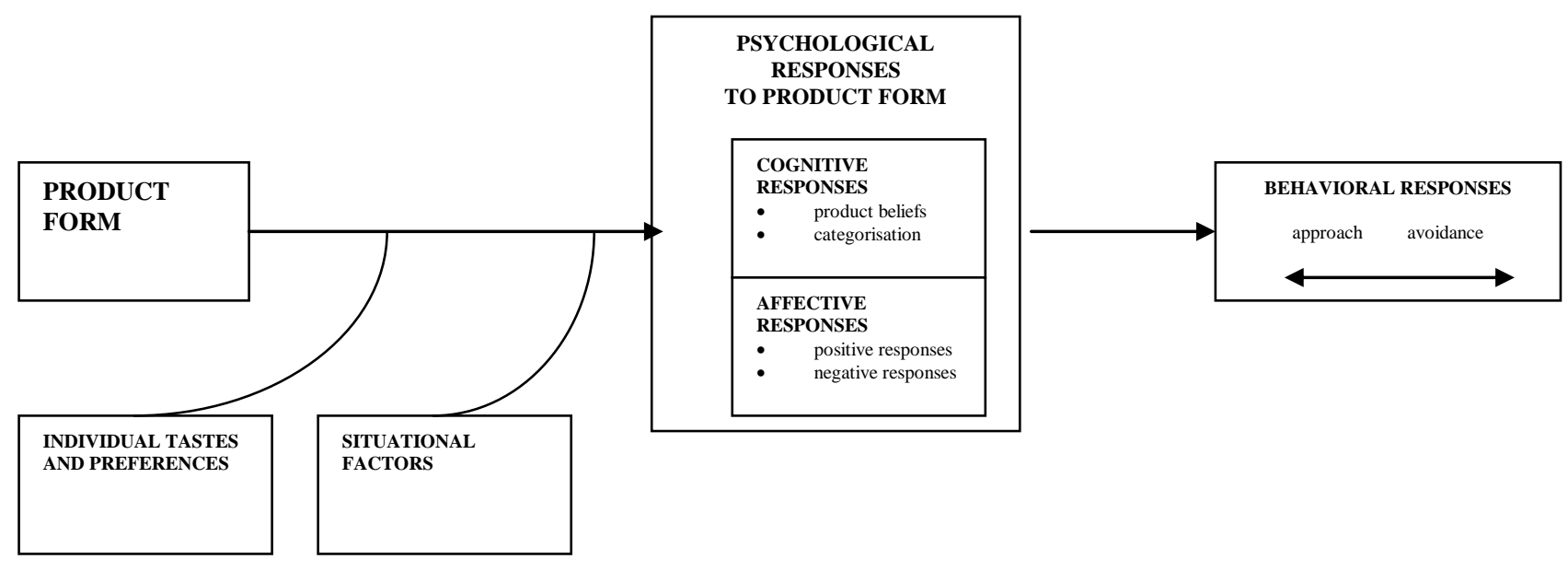

Figure 1

Adaption of Bloch's Model of Consumer Responses to Product Form

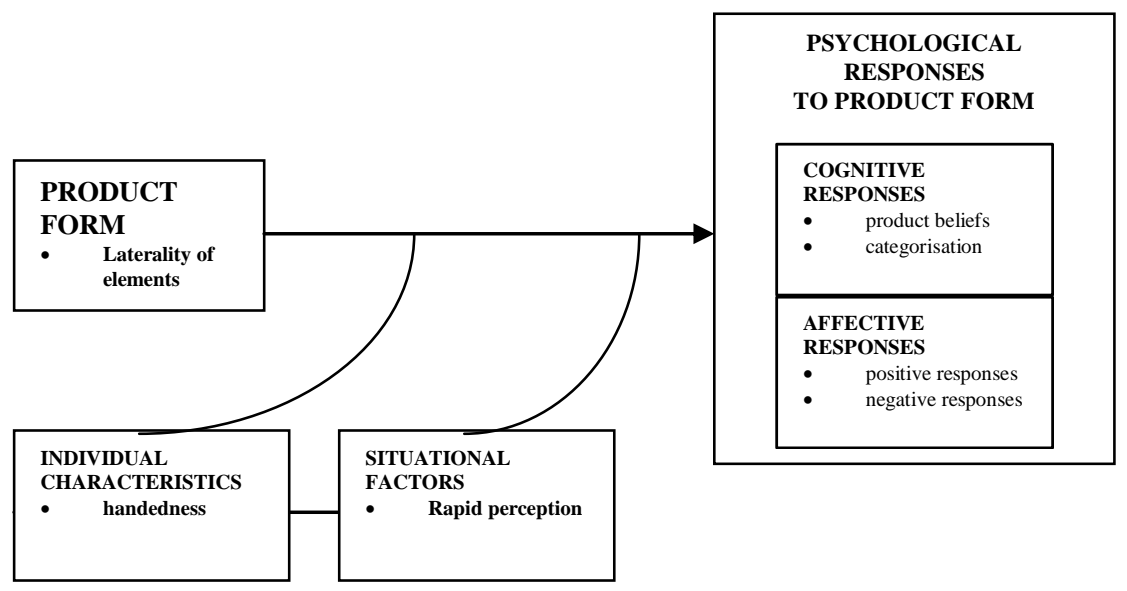

Figure 2 
Plate 1: Packaging Used in the Research 
Table I - Copy Recall

\begin{tabular}{|l|l|l|l|l|}
\hline Brand & Element & $\begin{array}{l}\text { \% correct recall } \\
\text { copy on right }\end{array}$ & $\begin{array}{l}\text { correct recall } \\
\text { copy on left }\end{array}$ & $\begin{array}{l}\text { Advantage with } \\
\text { copy on right }\end{array}$ \\
\hline PG Tips & promotion & 53 & 28 & $25^{*}$ \\
\hline & bag number & 38 & 34 & 4 \\
\hline Harrington Log & brand name & 12 & 1 & $11^{*}$ \\
\hline & product & 46 & 42 & 4 \\
\hline & flavour & 72 & 71 & 1 \\
\hline WW cookies & brand name & 32 & 26 & 6 \\
\hline Arctic Roll & brand name & 48 & 45 & 3 \\
\hline & product & 43 & 44 & -1 \\
\hline & other brand & 73 & 75 & -2 \\
\hline Overall & & 46.33 & 40.67 & $5.6^{*}$ \\
\hline
\end{tabular}

Base: 150 respondents

$* \mathbf{p}<0.05$ 
$\underline{\text { Table II - Recall of Pictorial Elements }}$

\begin{tabular}{|l|l|l|l|l|}
\hline Brand & Pack Element & $\begin{array}{l}\text { \% correct } \\
\text { picture on left }\end{array}$ & $\begin{array}{l}\text { \% correct } \\
\text { picture on right }\end{array}$ & $\begin{array}{l}\text { Advantage with } \\
\text { picture on left }\end{array}$ \\
\hline PG Tips & no of chimps & 80 & 54 & $26^{*}$ \\
\hline F Pizza & special price & 23 & 19 & 4 \\
\hline Harrington Log & no of slices & 47 & 35 & 12 \\
\hline WW cookies & no of cookies & 38 & 35 & 3 \\
\hline & fat reduction & 9 & 3 & 6 \\
\hline Overall & & 39.4 & 29.2 & $10.2^{*}$ \\
\hline
\end{tabular}

Base: 150 respondents

$* p<0.05$ 